\title{
Evapotranspiration estimation in the Brazil using NDVI data
}

\author{
Luciana Rossato $^{* a}$, Regina C. S. Alvaláa, Nelson J. Ferreira ${ }^{a}$, Javier Tomasella ${ }^{b}$ \\ ${ }^{a}$ Centro de Previsão de Tempo e Estudos Climáticos, Instituto Nacional de Pesquisas Espaciais, Av. \\ dos Astronautas, 1758 - Jd. da Granja, São José dos Campos (SP), Brazil, CEP 12227-010. \\ ${ }^{\mathrm{b}}$ Centro de Previsão de Tempo e Estudos Climáticos, Instituto Nacional de Pesquisas Espaciais, \\ Rodovia Presidente Dutra km39, Cachoeira Paulista (SP), Brazil, CEP 12630-000.
}

\begin{abstract}
The purpose of this study is to analyze the monthly mean spatial and temporal distribution of evapotranspiration (ET) during the 1981-2000 period in Brazil using remotely sensed data. The methodology involves the use of a relationship between ET and Normalized Difference Vegetation Index (NDVI). ET was estimated for the main Brazilian biomes through the Penman-Monteith method using climatological data from 194 Brazilian meteorological stations during the 1961-1990 period. NDVI data for the July 1981 to July 2000 period was obtained from Advanced Very High Resolution Radiometer (AVHRR) sensor on board the NOAA satellite. A relatively high correlation coefficient between ET and NDVI ( $r=0.81$ ) was found, showing a near linear relationship involving these variables. Also, the monthly mean ET over Brazil was estimated using NDVI data. The results showed that the ET rate in the Amazon region is not well defined because the maximum values occur after the rainy season, while for the Northeast Brazil, the highest ET values occur in according to period of rainy season. The annual cycle of ET is most defined in the Central region, with maximum values occurring in January to May period and minimum in September. In the South and Southeast regions, the annual cycle ET does not change very much. Finally, this study suggests that NDVI is an important variable for indirectly monitoring ET over large areas, thus with great potential for agronomical and climatic applications.
\end{abstract}

Keywords: Evapotranspiration, Normalized Difference Vegetation Index, AVHRR sensor.

\section{INTRODUCTION}

Evapotranspiration (ET) is the main transferring mechanism in the continuous ground-plant-atmosphere. Besides that it is an important variable for the hydrological cycle, crop efficiency and hydric stress detection among others. ET can be either estimated or measured from different approaches such as the energy balance method, the "eddy correlation" method and the aerodynamic method ${ }^{1}$. On the other hand, data from remote sensors in the thermal infrared spectral bands have been widely used to estimate ET to characterize the hydrological conditions and its influences in the vegetation specified areas. Kite and Droogers ${ }^{2}$ analyzed eight different methods of ET estimates in the west region of Turkey during the 1998 summer; they noticed that both the satellite and the FAO-24 methods were the most representative. The FAO method is relatively easy once it demands only the use climatological data besides being useful for operational applications and in the analyses of satellites data when there is lack of observations. On the other hand the satellite method is characterized by high spatial and temporal resolution, especially in the case of Landsat and NOAA satellites. For this reason it provides accurate ET estimates due to the availability of data spatially distributed.

ET distribution in broad areas may be estimated through the Normalized Difference Vegetation Index (NDVI) using data from the visible and near infrared sensors from Landsat or from the NOAA/AVHRR (National Oceanic and Atmospheric Administration/Advanced Very High Resolution Radiometer) satellite. Mathematically, if L1 is the radiance in channel 1 (visible) of the AVHRR and L2 is the radiance in channel 2, NDVI is defined as (L2 - L1)/(L2 + L1). NDVI values are high when the green plants cover one pixel and is rather low when the green plants are not present $^{3}$. Thus NDVI is highly correlated to vegetation parameters such as green biomass, leap area index (LAI) and the intercepted photosynthetic active radiation (IPAR) ${ }^{4}$.

In the last decades, many studies have highlighted the advantages of vegetation index to estimate ET once temperature data derived from satellite sensors integrate the topography effects, surface water and the wind which direct or indirect 
change ET flux. Kerr et al. ${ }^{5}$, making use of AVHRR data found a high correlation between NDVI and ET for cultivable areas in three regions on the west Africa. Their results have shown that besides an existing linear relation with a high correlation, there is a decreasing lag around 20 days between the occurrence of a physiological factor (ET) and NDVI. Lo et al. $^{4}$ related the vegetation index and the real ET over Africa and noticed that the annual ET is correlated to the integrated NDVI, that is, with the NDVI from adding up the positive values (NDVI - 0.05) for the months with average temperature higher than $0^{\circ} \mathrm{C}$. Based on this study they have also observed that the integrated NDVI can be used just as an estimator of the primary productivity balance (NPP) and the actual ET on an annual basis. The quantification of these processes on a monthly basis will demand a more realistic description of the physical interactions between the vegetation and radiation elementary processes. Srivastava et al. ${ }^{6}$ studied the relation between NDVI and transpiration in dry regions of India and realized that the correlation between both variables was significantly high. Di Bella et al. ${ }^{7}$ applied multiple regression analyses to relate ET estimated from water balance technique with NDVI data from AVHRR sensor. Using this estimate based only on remote sensor data it was possible to map ET of the Pampa region, the main agricultural region of Argentina. The obtained results have pointed out that the relationship between the spectral data and the ET was more sensitive to the temporal distribution than the spatial one. Sun et al. ${ }^{8}$ have established a relation between annual ET, integrated NDVI and the Relative Humidity Index (RMI). Based on this relation, both temporal and spatial annual ET distributions were estimated to the Yellow River Basin, China, during the 1982/2000 period; the results have shown that the integrated NDVI may be effectively used to estimate the annual ET, with $90 \%$ accuracy in the basin.

Considering the ET importance, the vast territorial extent of Brazil and the consequent spatial and temporal variety of NDVI data, the aim of this study is to develop a relationship between ET estimated by the Penman-Monteith method and NDVI data to estimate the monthly average ET for all the Brazilian territory for the 1981-2000 period.

\section{METHODOLOGY}

In this study, the temporal and spatial distribution of the monthly average ET for the 1982-2000 period was estimated from the relationship between ET, calculated by the Penman-Monteith method using climatological data ${ }^{9}$, and NDVI from AVHRR data.

\subsection{Evapotranspiration estimates from climatological data}

For regions in which temperature, wind and radiation data are available, the United Nations Organization for Nutrition and Agriculture (FAO) has adopted the Penman-Monteith method as a standard for reference ET estimates as well as many micro-meteorological characteristics associated to the model and the considered location.

According to Allen et al. ${ }^{10}$, the Penman-Monteith expression for the figure of the ET is given by:

$$
\lambda \mathrm{ET}=\frac{\Delta\left(\mathrm{R}_{\mathrm{n}}-\mathrm{G}\right)+\rho_{\mathrm{a}} \mathrm{c}_{\mathrm{p}}\left(\mathrm{e}_{\mathrm{s}}-\mathrm{e}_{\mathrm{a}}\right) / \mathrm{r}_{\mathrm{a}}}{\Delta+\gamma\left(1+\mathrm{r}_{\mathrm{s}} / \mathrm{r}_{\mathrm{a}}\right)}
$$

where $R_{n}$ is the net radiation $\left(\mathrm{kJ} \mathrm{m}^{-2} \mathrm{~s}^{-1}\right), \mathrm{G}$ is the soil heat flux $\left(\mathrm{kJ} \mathrm{m}^{-2} \mathrm{~s}^{-1}\right),\left(\mathrm{e}_{\mathrm{s}}-\mathrm{e}_{\mathrm{a}}\right)$ represent the vapour pressure deficit of the air $(\mathrm{kPa}), \rho_{\mathrm{a}}$ is the mean air density at constant pressure $\left(\mathrm{kg} \mathrm{m}^{-3}\right), \mathrm{c}_{\mathrm{p}}$ is the specific heat of the air $\left(\mathrm{kJ} \mathrm{kg}^{-1}{ }^{\circ} \mathrm{C}^{-1}\right), \Delta$ represents the slope of the saturation vapour pressure temperature relationship $\left(\mathrm{kPa}^{\circ} \mathrm{C}^{-1}\right), \quad \gamma$ is the psychrometric constant, and $\mathrm{r}_{\mathrm{s}}$ and $\mathrm{r}_{\mathrm{a}}$ are the (bulk) surface and aerodynamic resistances $\left(\mathrm{s} \mathrm{m}^{-1}\right)$.

Thus, the potential ET, monthly average, for all the Brazilian territory during the 1961-1990 period was estimated for different kinds of biomas, considering climatological data from INMET ${ }^{9}$.

\subsection{Relation between ET and NDVI}

As previously mentioned, many researches have been developed in order to establish the relation between ET and NDVI $^{4,5,6}$. Srivastava et al. ${ }^{6}$ have developed a relation between integrated NDVI and the transpiration, while Kerr et al. ${ }^{5}$ and Lo et al. ${ }^{4}$ have estimated ET using only NDVI data. In the model developed by Di Bella et al. ${ }^{7}$, the surface temperature effect was also considered, using thermal infrared sensors data. 
In this study a relationship between estimated ET and NDVI data was obtained using linear regression analyses. ET values were calculated by the Penman-Monteith method, using climatological data for 193 brazilian meteorological stations during the 1961-1990 period.

To study the dependency of the relationship between ET and NDVI data for the 193 meteorological stations, the data were combined according to the different classes of vegetation cover in Brazil, as defined by SSiB model (Fig. 2).

Eventually, the temporal and spatial distribution of the monthly average potential ET during the 1981-2000 period was obtained for all the Brazilian territory through a linear regression analyses between the ET and the NDVI data.

\section{DATA}

\subsection{Evapotranspiration data}

Rossato et al. ${ }^{9}$ have estimated potential ET using the Penman-Monteith method using wind data, monthly average temperature, relative humidity, total insolation and atmospheric pressure for the 1961-1990 period from meteorological stations distributed in Brazil and operated by the Instituto Nacional de Meteorologia - INMET (Fig 1).

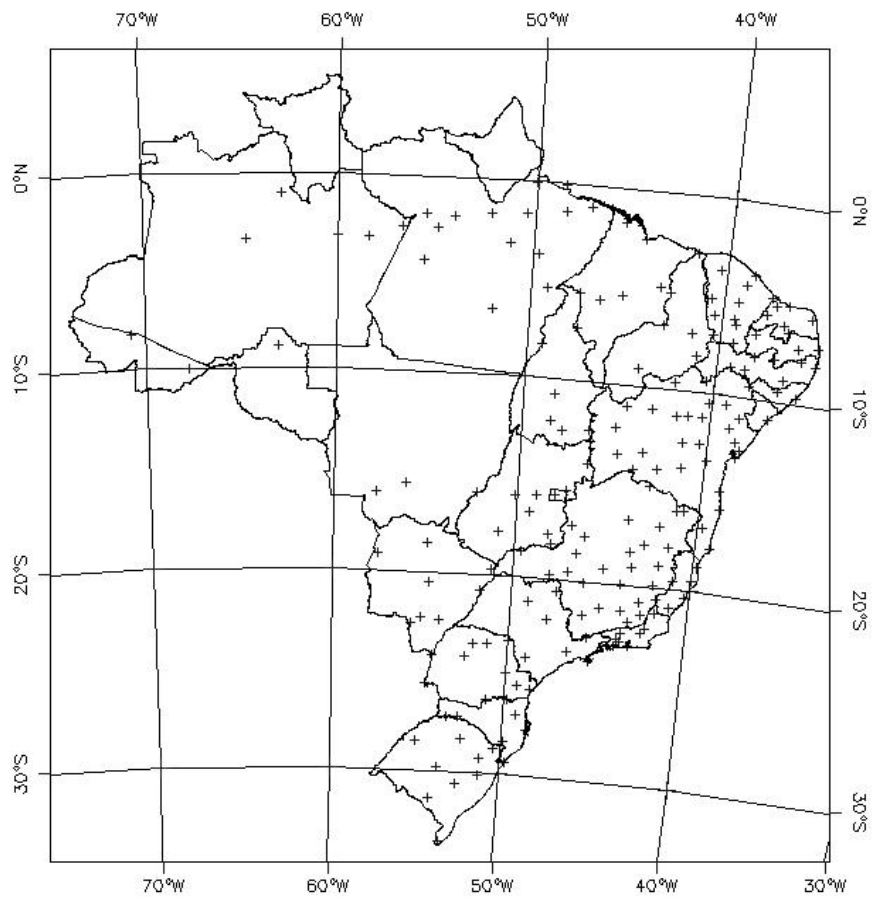

Figure 1: Location of meteorological stations of INMET in Brazil.

The data described above were the base for estimating potential ET, and the results were adjusted considering different classes of vegetation cover, and making use of the vegetation map from the AVHRR sensor -classified according to the biomas defined by the SSiB surface model (see Fig. 2) Thus the monthly mean potential ET for all the Brazilian territory during the 1961-1990 period was estimated for different types of biomas, from climatological data 9 


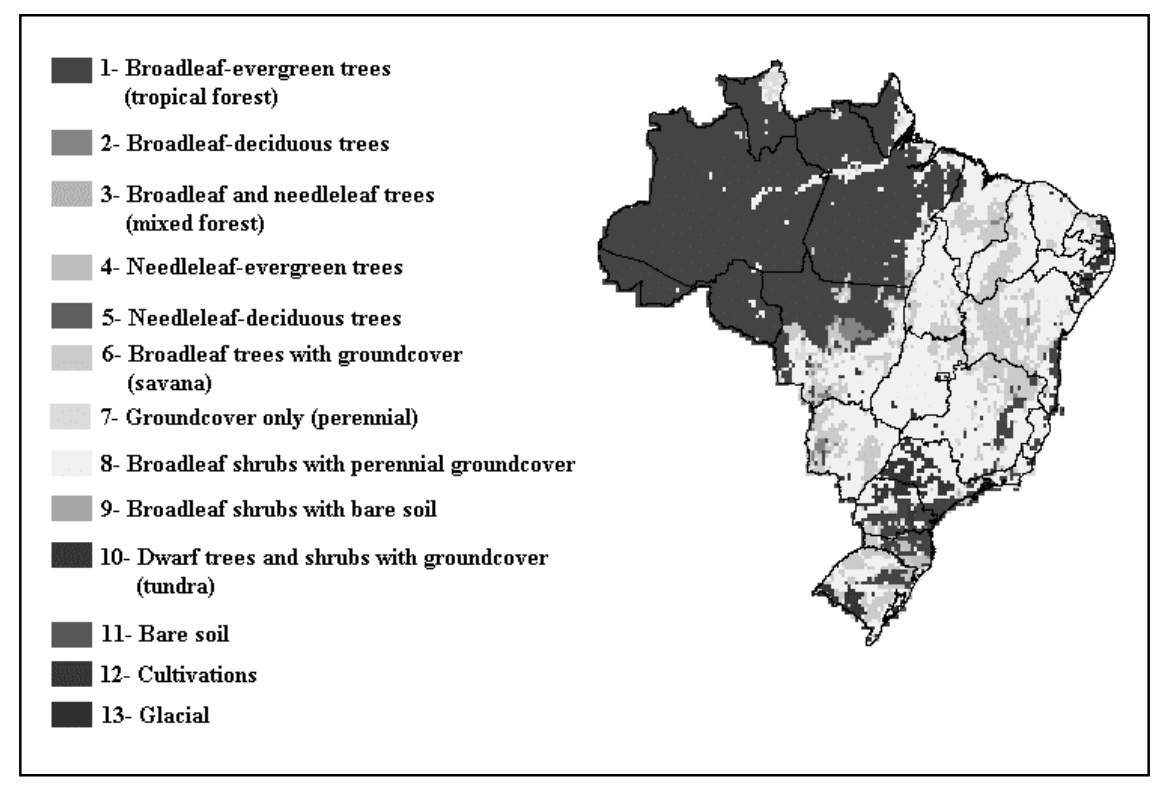

Figure 2. Vegetation Map used in the $\mathrm{SSiB}$ model (Resolution: $0.25^{\circ} \times 0.25^{\circ}$ ).

\subsection{NDVI Data}

NDVI data were produced by Global Inventory Monitoring and Modelling Studies (GIMMS) from the Group at National Aeronautics and Space Administration/Goddard Space Flight Center (NASA / GSFC) during the 1981-2000 period. These data are derived from channels 1 and 2 of the AVHRR sensor onboard the NOAA ( NOAA 7, 9, 11 and 14) satellites. The NDVI was calculated as the normalized difference of the corrected reflectance of the near infrared channels $(0,725-1,10 \mathrm{~mm})$ and the visible $(0,58-0,68 \mathrm{~mm})$ using AVHRR GAC data (Global Area Coverage, 4-km resolution). The monthly compositions of the images were made available for South America with spatial resolution of $8 \mathrm{~km} \times 8 \mathrm{~km}$. The data over oceanic areas were masked with unity value ${ }^{11}$.

\section{RESULTS}

A significant relationship among NDVI annual average values (observed data for the July 1981 to July 2000 period) in, and the annual average ET for the 1961-1990 period was found for each type vegetation cover in Brazil. Figure 3 illustrates the pattern of the potential ET and the NDVI for the different kinds of biomas.

The relationship between e ET and the obtained NDVI shows a good correlation. This procedure based on the selected meteorological stations was done considering the following six different kinds of vegetation cover along the Brazilian territory : broadleaf-evergreen trees (tropical forest), broadleaf-deciduous trees, broad leaf trees with groundcover (savana), groundcover only (perennial), broadleaf shrubs with perennial groundcover and cultivations (corresponding to the biomas 1,2,6,7,8 and 12 defined by the SSiB model, respectively). In Figure 3 it is shown that only one point did not match the straight line in which the data are associated to bioma 8. Observing the regions associated to each station and the correspondent vegetation cover stands out that bioma 8 from the SSiB model is not representative of the specified places suggesting the presence of errors in the correlation. Otherwise despite this dispersion the estimated ET and the NDVI data were very well correlated $(r=0,81, n=193$, Student $T$ test at $5 \%$ significance with $\mathrm{p}<0.0001)$. The obtained correlation is similar to other results shown in the literature, for example, as in the Di Bella et al. ${ }^{7}, \mathrm{r}=0,79$, and Sun et al. ${ }^{8}$, $\mathrm{r}=0,768$. Yet, as also highlighted by Kerr et al. ${ }^{5}$, the obtained correlation allows one to conclude that the NDVI is proportional to the vaporized water into the atmosphere. Thus the following linear relationship was obtained:

$$
\mathrm{ET}=-0.24898+0.00874 \mathrm{NDVI}
$$


where ET is in mm/day e o NDVI is dimensionless and multiplicated by 1000.

From this equation one can compare the average monthly potential ET, estimated by the Penman-Moteith method and from NDVI data, as shown in Fig 4.

Analyzing Fig 4 it is seen that annual potential ET values estimated from NDVI data are close to the ones calculated by the Penman-Monteith method for the different types of biomas. Finally, taking into account the equation obtained by linear regression, it was estimated the monthly average ET for all the Brazilian territory during the 1981-2000 period (Figures 5 and 6) using NVI data.

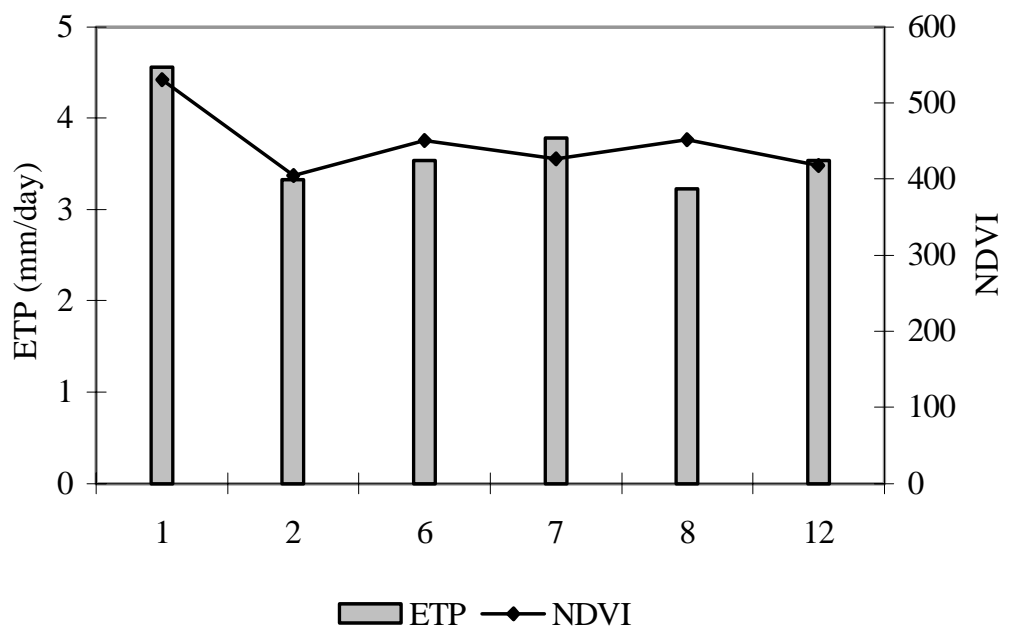

Figure 3: Annual average of the potential ET and NDVI for the different kinds of biomas of the SSiB model in Brazil.

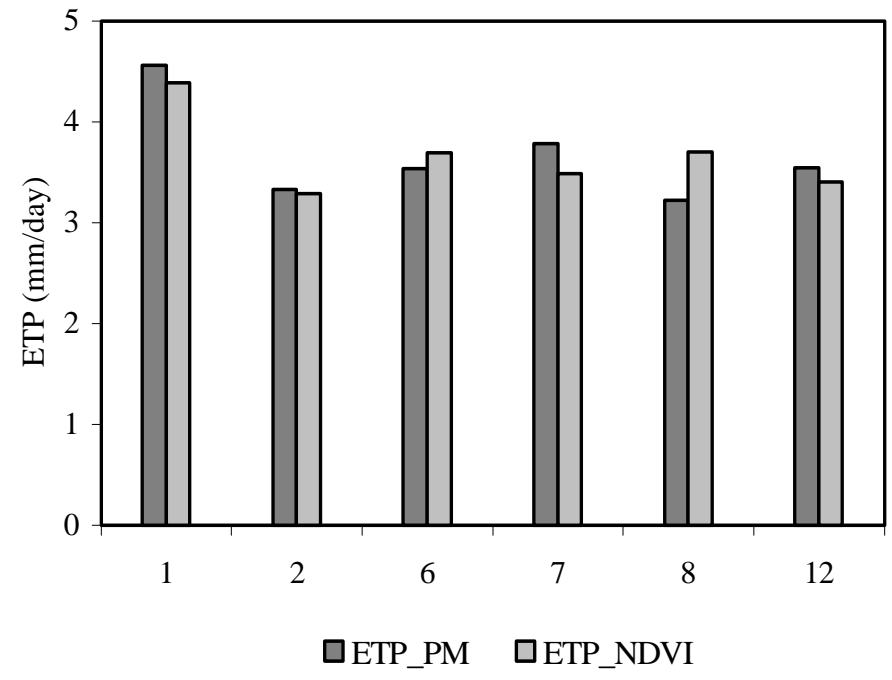

Fig. 4: Annual potential ET average changes based on the Penman-Monteith method and estimated by NDVI for the different types of SSiB model biomas. 
Figures 5 and 6 show the temporal and spatial distribution of the potential monthly average ET estimated through a linear regression between ET (using average values obtained by the Penman-Monteith method for the 1961-1990 period), and NDVI data for the 1981-2000 period. The results show that ET in the Amazon region does not shows a well defined cycle: maximum values (5-6 mm/day) occurs between June and July in the South (North) of the State of Pará (Mato Grosso), while minimum values (2-3 mm/day) are observed during September. This behavior can be explained by the low correlation involving ET and NDVI for bioma 8 in the SSib model, which corresponds to the broadleaf shrubs with perennial groundcover. Almeida e Batista ${ }^{12}$, analyzing the correlation between the vegetation index and the precipitation in the Amazon region obtained similar results. For the Northeast region of Brazil, the highest indexes of ET were observed during February and May, the raining season period in this region, while the minimum values occurred from September to December. Due to regional characteristics, ET rate is distinct in large areas, that is, the seashore coast of the northern Brazil and the inner regions have a higher temperature than along the eastern coast. Furthermore, the east coast is more affected by meteorological systems, such as the sea breeze, easterly waves and cold fronts that comes from the south region of the country; while the atmospheric circulation over the Northeastern region is mainly drawn by the orographyc effects ${ }^{13}$. In the middle-east, the annual cycle of the ET is well defined, with maximum values occurring during January and May and the minimum one in September (dry period) varying between 1-2 $\mathrm{mm} /$ day in the north of Minas Gerais State. In the Southeast Brazil, it is observed a decrease in ET values between June and September (period of low NDVI values due to the dry period). In the Southern Brazil it is observed that the average ET rate has not shown large changes, the estimated values are 3-6 mm/day. This region is characterized by high precipitations indices throughout the year ${ }^{14}$.

In general it is observed that ET estimates through NDVI data shows a well-defined annual cycle for regions characterized by raining and dry periods. In a study of NDVI variability in Brazil through cluster analysis, Gurgel et al. ${ }^{15}$ also observed that several types of vegetation cover in regions with well defined rainy and dry periods, such as the case of caatinga and the savanna which show a well characterized annual cycle and a fast response to rain occurrences. Besides that, it was noticed that the NDVI distribution for dense and greener vegetation throughout the year, e.g. in the Amazon forest shows significant changes when climatic anomalies such as the EL Niño phenomenon occurs. The occurrence of El Niño episodes during the 1981-2000 period could explain the observed pattern of the ET annual cycle Amazon Region. 


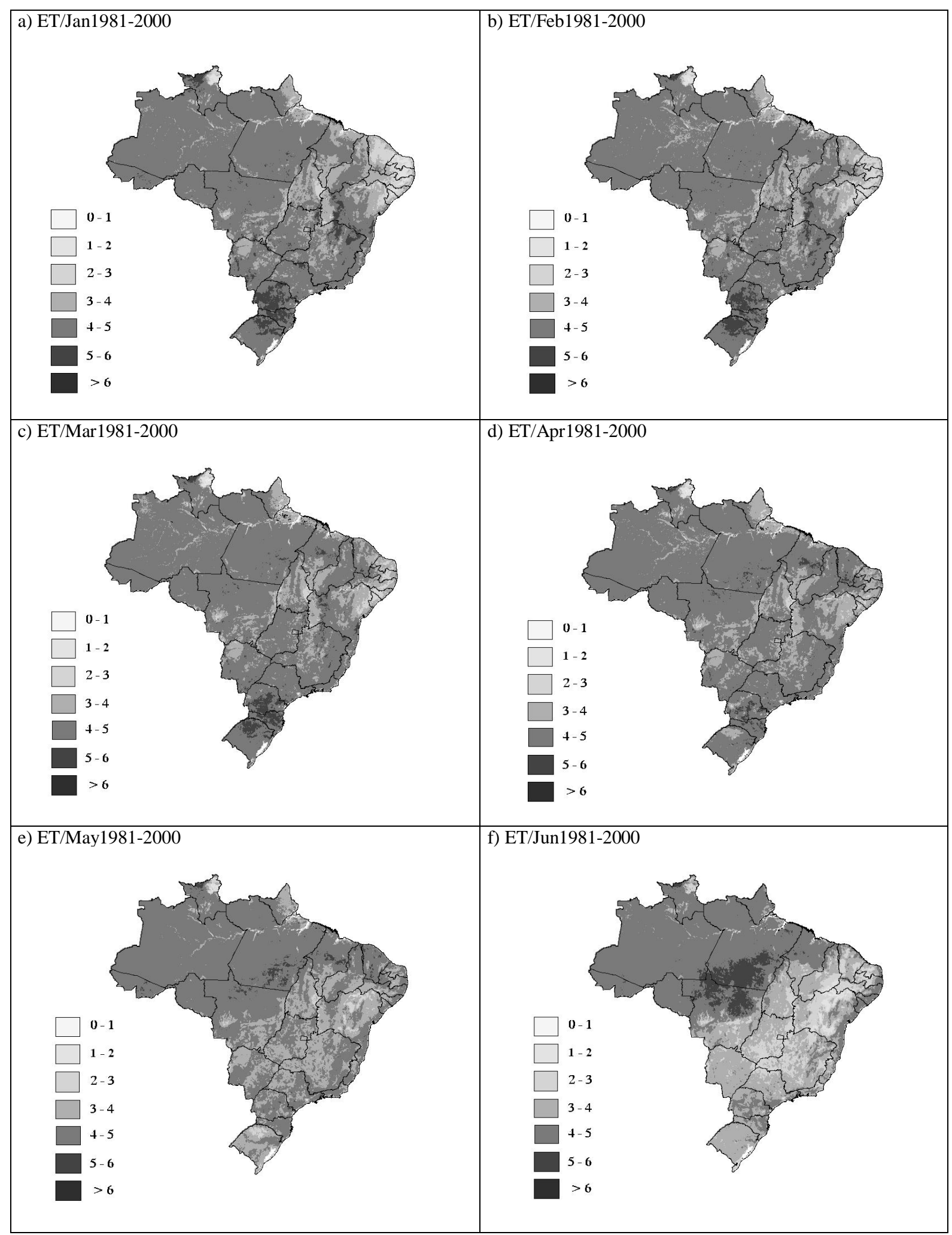

Figure 5: Monthly potential ET average for Brazil during the 1981-2000 period: a) January; b) February; c) March; d) April; e) May and f) June. 


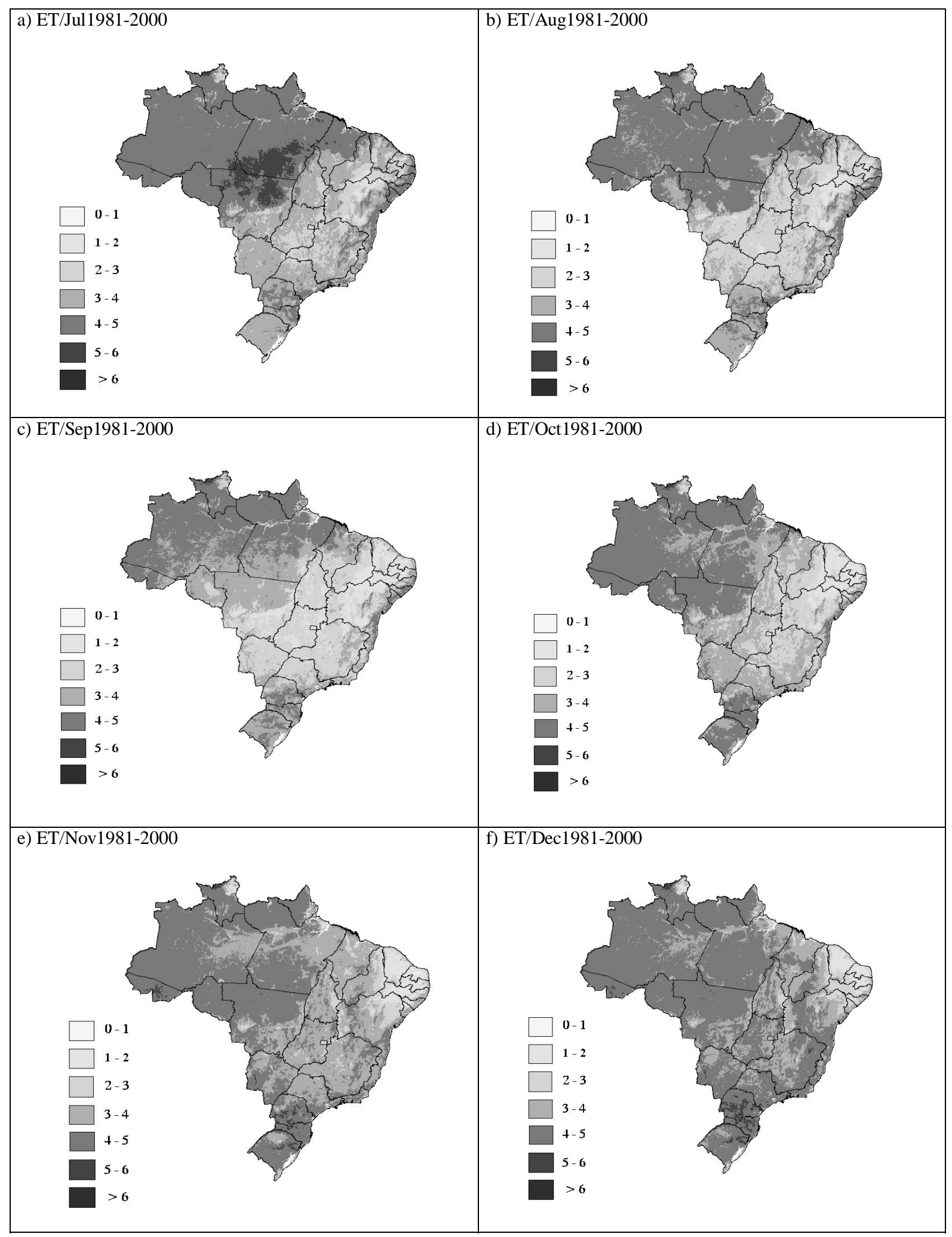

Figure 6: Monthly potential ET average for Brazil during the 1981-2000 period: a) July; b) August; c) September; d) October; e) November and f) December. 


\section{CONCLUSIONS}

In this study the monthly ET average (1981-2000) for all the Brazilian territory was estimated from remote sensing data using a linear regression between ET and NDVI/AVHRR data, whose correlation coefficient was 0.81. Also, it was observed that even if one considers the different temporal and spatial resolutions, the ET and the NDVI data were well correlated for the different types of Brazilian biomas. This correlation can be improved using surface temperature data from satellite as suggested by Di Bella et $\mathrm{al}^{7}$, as well as considering other types of biomas that are classified by the land use changes and making use of the same temporal distribution for ET and NDVI data.

From the monthly average distribution of ET it was observed that its annual cycle is associated to the vegetation types found in regions, with evident rainy and dry periods. Although it is highlighted that for micro-meteorological studies, the relation between ET and NDVI should be carefully understood for each vegetation cover from the place being studied and with a higher level of temporal and spatial details.

\section{ACKNOWLEDGMENTS}

This work received financial support from the Coordenação de Aperfeiçoamento de Pessoal de Nível Superior (CAPES).

\section{REFERENCES}

1. A. R. Pereira, N. A. V. Nova, G. C. Sediyama, Evapo(transpi)ração, Piracicaba: FEALQ, 1997. 183p.

2. G. W. Kite, P. Droogers, "Comparing evapotranspiration estimates from satellite, hydrological models and field data, Journal of Hydrology", 229, 3-18, 2000..

3. S. Q. Kidder, T. H. Vonder Haar, Satellite meteorology: an introduction, United Kingdom Edition, Academic Press. 466p, 1995.

4. S. C. D. Lo, E. Mougin, J. P. Gastellu-Etchegorry, "Relating the global vegetation index to net primary productivity and actual evapotranspiration over Africa", International Journal of Remote Sensing, 14, 1517-1546, 1993.

5. H.Kerr, J. Imbernon, G. Dedieu, O. Hautecoeur, J. P.Lagouarde, B. Seguin, "NOAA AVHRR and its uses for rainfall and evapotranspiration monitoring", International Journal of Remote Sensing, 10, 847-854, 1989.

6. S. K. Srivastava, , V. Jayaraman, P. P. Nageswara Rao, B. Manikiam, M. G. Chandrasekhar, "Interlinkages of NOAA/AVHRR derived integrated NDVI to seasonal precipitation and transpiration in dryland tropics", International Journal of Remote Sensing, 18, 2931-2952, 1997.

7. C. M. Di Bella, C. M. Rebella, J. M Paruelo, "Evapotranspiration estimates using NOAA AVHRR imagery in the Pampa region of Argentina", International Journal of Remote Sensing, 21, 4, 791-797, 2000.

8. R. Sun, X. Gao, C. M. Liu, X. W. Li, "Evapotranspiration estimation in the Yellow River Basin, China using integrated NDVI data", International Journal of Remote Sensing, 25, 13, 2523-2534, 2004.

9. L Rossato, R. C. S. Alvala, J. Tomasella, "Variação espaço-temporal da umidade do solo no Brasil: analise das condições médias para o período de 1971-1990", Revista Brasileira de Meteorologia, 19, 2, 113-122, 2004.

10. R. G. Allen, L. S., Pereira, D. Raes, M. Smith, "Crop evapotranspiration: guidelines for computing crop water requirements", Rome, Italy: FAO Irrigation and Drainage Paper, n.56, 1988. 300p.

11. N. Dessay, H. Laurent, L. A. T. Machado, Y. E. Simabukuro, G. T. Batista, A. Diedhiou, J.Ronchail, "Comparative study of the 1982-1983 and 1997-1998 El Niño events over different types of vegetation in South America", International Journal of Remote Sensing, 25, 20, 4063-4077, 2004.

12. E. S. Almeida, G. T. Batista, "Índice de vegetação versus precipitação na Amazônia, In: Simpósio Brasileiro de Sensoriamento Remoto", Santos. Anais...Santos. Instituto Nacional de Pesquisas Espaciais, 1998, CD-Rom.

13. J. B. Bastos , J. M. Souza, T. V.Ramana Rao, "Potential evapotranspiration estimates for Northeast Brazil using GOES-8 data", Revista Brasileria de Engenharia Agrícola e Ambiental, 4, 3, 348-354, 2000.

14. A. M. Grimm, V. R. Barros, M. E. Doyle, "Precipitation anomalies in southern Brazil associated with El Niño and La Niña events", Journal of Climate, Boston, v.11, n.11, p. 2863-2880, 1998.

15. H. C. Gurgel, N. J. Ferreira, , A. J. B.Luiz, "Estudo da variabilidade do NDVI sobre o Brasil, utilizando-se a análise de agrupamentos”, Revista Brasileira de Engenharia Agrícola e Ambiental, 7, 1, 85-90, 2003. 